\title{
El Estado, la familia y el mercado. Arreglos institucionales para atender las necesidades generadas por el envejecimiento demográfico
}

\author{
Carlos Welti-Chanes
}

\author{
Universidad Nacional Autónoma de México, México
}

\section{Resumen}

En este artículo, se analiza el papel de los arreglos institucionales en tres ámbitos de acción: el Estado, la familia y el mercado, para atender las necesidades del envejecimiento demográfico, a través de una perspectiva que pone énfasis en las necesidades que aparecen en las diversas etapas de la vida del individuo. La intención del texto es hacer evidente que, aunque las instituciones en los tres ámbitos mencionados contribuyen a satisfacer las necesidades que surgen con el envejecimiento, es el Estado quien cumple el rol fundamental, la familia está limitada para cumplir esta función y al mercado guiado por la búsqueda de la ganancia, no será la organización que pueda enfrentar los problemas del envejecimiento.

Palabras clave: Envejecimiento, política social, instituciones.

\section{Abstract}

The State, the family and the market. Institutional arrangements to meet the needs generated by demographic aging

In this article, the role of institutional arrangements in three areas of action is analyzed: the State, the family and the market, to meet the needs of demographic aging, through a perspective that emphasizes the needs that appear in the various stages of life of the individuals. The intention of the text is to make clear that, although the institutions in the three areas mentioned contribute to satisfy the needs that arise with aging, it is the State that fulfills the fundamental role, the family is limited to fulfill this function and the guided market the search for profits will not be the organization that can face the problems of aging.

Key words: Aging, social policy, institutions. 


\section{INTRODUCCIÓN}

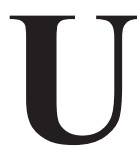

na hipótesis inicial en este texto, es que, la necesidad de asegurar la sobrevivencia de los individuos, da origen a la sociedad y obliga a establecer relaciones regidas por lo que Rousseau denomina el "contrato social".

Así, las acciones colectivas y los arreglos institucionales en la sociedad tienen en última instancia este objetivo que, a través de la historia de la humanidad, se ha visto reflejado en el incremento de la esperanza de vida.

Esta hipótesis, por cierto, justifica el cuidado que debe otorgarse a los viejos y desacredita los argumentos que ven en la sobrevivencia de los mismos, un atentado a la sobrevivencia de generaciones más jóvenes. ${ }^{1}$

Aunque Keynes expresó la frase "en el largo plazo todos estaremos muertos", ${ }^{2}$ para sostener que en el análisis de situaciones actuales tiene poco sentido hablar de largo plazo, al proponer medidas para enfrentar las consecuencias del envejecimiento demográfico, es indispensable hacer referencia al largo plazo, no sólo porque la evolución de la humanidad muestra que, al tomar como referencia la sobrevivencia de los individuos, éste horizonte temporal es cada vez más largo y por tanto, nuestra esperanza de vida mayor, ${ }^{3}$ también porque el envejecimiento demográfico es un proceso que involucra a varias generaciones y por tanto, éste es un tema de largo plazo que nos afecta a todos.

En la historia de la humanidad, en etapas en las que no se contaba con la tecnología para enfrentar las enfermedades, se desconocían los mecanismos de su transmisión y no se tenían los conocimientos y la infraestructura para prever y resistir las consecuencias de los fenómenos naturales que incidían sobre las condiciones de vida de los seres humanos, la sobrevivencia colectiva, es decir, la sobrevivencia del grupo de referencia, se buscaba a través de la promoción de elevados niveles de fecundidad, que aseguraban

\footnotetext{
${ }^{1}$ El ministro de Japón, Taro Aso, refiriéndose a los viejos de su país, declaró que deben darse prisa y morir para aliviar los gastos del Estado en su atención médica (EL País, enero 22 de 2013). Por su parte, previamente, el Fondo Monetario Internacional a través de su directora gerente Christine Lagarde, exigió que se recorten las prestaciones y se retrase la edad de jubilación ante "el riesgo de que la gente viva más de lo esperado", esta idea fue expresada en el Informe Financiero Mundial 2012.

${ }^{2}$ La frase de J. M. Keynes aparece en el Tratado sobre la Reforma monetaria. Textualmente, el autor expresa: "But this long run is a misleading guide to current affairs. In the long run we are all dead" (Keynes, 1923: 80).

${ }^{3}$ La época en la que Keynes nació, en el Reino Unido, su país, la esperanza de vida no superaba los 50 años.
} 
que la familia, o el grupo social más amplio, no desapareciera como resultado de los elevados niveles de mortalidad que se padecían.

En organizaciones como la familia, la escuela o la iglesia en cualquiera de sus vertientes religiosas y las agencias del Estado, durante siglos, se han fomentado conductas para mantener una alta fecundidad, por medio de prácticas como: inicio temprano de las relaciones conyugales y relaciones sexuales cuyo fin es exclusivamente la procreación, y la prohibición del aborto y de la anticoncepción; incluso, en algunas sociedades se aceptaba la poligamia con este objetivo. La elevada fecundidad, reflejada en las familias numerosas y la convivencia generacional de corta duración, caracterizaron a la historia de la humanidad hasta épocas relativamente cercanas.

La combinación de altas tasas de fecundidad y mortalidad, determinó una distribución por edad de la población en la cual los niños y los jóvenes, constituían las mayores proporciones en la denominada pirámide de edad.

Es precisamente, la distribución por edad de la población, la que en gran medida determina el curso de acción de organizaciones como el Estado o la familia, para satisfacer las necesidades de sus miembros e incluso, para el mercado, la estructura por edad de una población y su nivel de ingreso, son fundamentales para planear la producción de mercancías y servicios.

Producto del desarrollo científico y sus aplicaciones y de la creación de instituciones públicas que incidieron sobre las condiciones de vida de la población, la estructura demográfica se transformó. En países como México, en unas cuantas décadas, las demandas para satisfacer las necesidades de la población asociadas a su propia dinámica, se han modificado radicalmente, junto con la distribución por edad.

Una sociedad con elevados niveles de fecundidad debe atender las necesidades de una población joven y debe ofrecer servicios de cuidado de la salud, educación y trabajo para sus integrantes y para sus nuevos miembros que en números crecientes se incorporan a ella cada año. Las organizaciones que caracterizan a una sociedad moderna, además de atender las necesidades de cada nueva generación, deben responder a las demandas de una población de adultos que envejece y que en el pasado apenas era visible.

La intención de este texto es mostrar como el Estado, la familia y el mercado responden a las necesidades asociadas al envejecimiento demográfico, a partir de los arreglos institucionales creados con este fin.

En todo tipo de sociedad, es posible identificar la forma en que Estado, familia y mercado interactúan con el objetivo ya mencionado, de acuerdo con el modelo económico vigente y la evolución histórica de la sociedad que, a través del tiempo, crea determinado tipo de organizaciones. 
Con este propósito, resulta útil identificar el tipo de necesidades que deben ser satisfechas a lo largo del ciclo de vida de los individuos y la manera en que éstas son satisfechas a través de distintos arreglos institucionales. Gráficamente se pueden representar en un triángulo estos arreglos institucionales ocupando cada uno de sus vértices los ámbitos que les dan origen, de tal manera que en su superficie se ubique la organización que responde a determinadas necesidades según la preeminencia que adquiere el Estado, la familia o el mercado.

Figura 1: Ubicación de los arreglos institucionales para atender las necesidades de la población

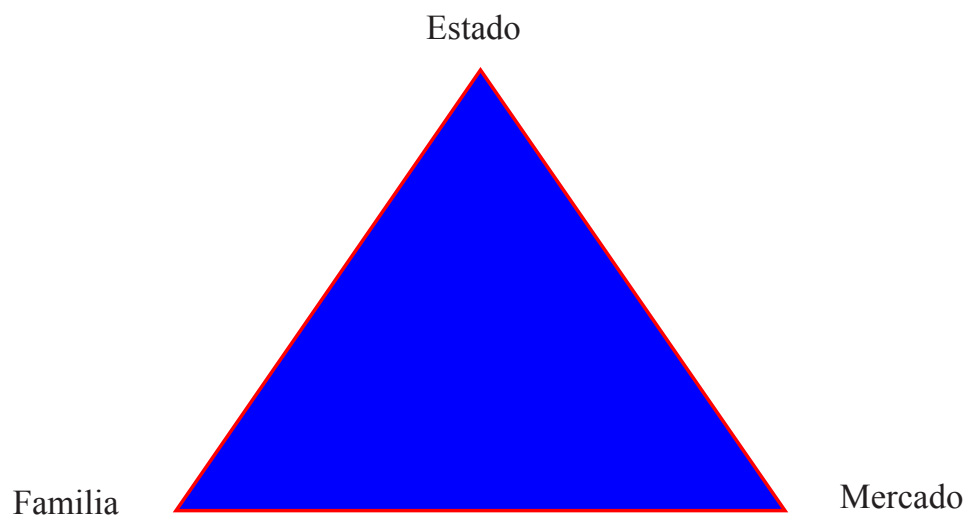

\section{El PaPel del Estado, la faMilia Y El MerCado en la SATiSfacción DE LAS NECESIDADES DE LOS GRUPOS POBLACIONALES}

De manera introductoria, se debe sostener que los seres humanos somos individuos con necesidades y recursos no solamente materiales y, por tanto, este principio debe guiar las acciones que desde diversos ámbitos pretendan responder a estas necesidades. Concretamente, la sociedad a través de sus organizaciones, además de satisfacer necesidades individuales elementales como alimentación, salud o vivienda, debe ser capaz de proveer educación y crear las condiciones para el desarrollo intelectual y el aprovechamiento del tiempo libre. Esto significa que la satisfacción de una cierta necesidad debe ser condición para generar otra. En otras palabras, cada vez que se satisface una necesidad aparece otra y es éste, el mecanismo que ha impulsado el desarrollo de una sociedad.

Una perspectiva útil en el abordaje de la definición de acciones para atender las necesidades del ser humano como parte de un grupo poblacio- 
nal es identificar éstas a lo largo del ciclo vital y de manera adicional considerar que, no son sólo las necesidades básicas que permiten la sobrevivencia las que deben atenderse, además, como ya se mencionó, aquellas cuya satisfacción es un insumo para el desarrollo y que permiten que individuo y sociedad se transformen.

Maslow (1943) propuso una clasificación de las necesidades en un modelo jerárquico, que ha sido representado gráficamente por una pirámide y que, en la actualidad, sería denominado mapa mental por su intención didáctica.

En el caso de las necesidades básicas ubicadas en el ámbito fisiológico, aunque similares por su naturaleza en cada etapa de la vida, la manera en que se satisfacen las diferencia asociadas a los procesos biológicos característicos de cada una de ellas.

Alimentación, protección contra las inclemencias del clima, descanso u ocio, por ejemplo, junto con otras que no son necesidades básicas, se modifican a lo largo de las edades del ser humano, y son el resultado del desarrollo físico e intelectual de las personas. De manera significativa, están asociados a los roles que a cada individuo le toca desempeñar; es decir, a las pautas de conducta que se espera deben cumplir y que se asignan a lo largo de la existencia de las personas y que cada sociedad ubica en etapas particulares del ciclo de vida; etapas definidas por eventos que marcan el paso de una a otra, visibles con mayor claridad conforme la sociedad se desarrolla. $^{4}$

Es necesario, por cierto, prestar especial atención a los roles determinados socialmente, porque son éstos los que dan origen a los arreglos institucionales para atender las necesidades de la población. ${ }^{5}$

Así, la infancia, la adolescencia, la edad adulta y la vejez, están asociadas a roles y eventos definitorios que son el resultado del desarrollo y de la inserción del individuo en la estructura social y son estas condiciones las que le dan mayor significación a uno o más roles.

En la infancia se es un ser dependiente, que debe asumir los códigos de conducta que le transmiten otras personas en su hogar o en las organizaciones dedicadas a su cuidado y que tienen como objetivo contribuir a su crecimiento físico e intelectual. Las actividades lúdicas que promueven su desarrollo ocupan una buena parte de la existencia porque éstas tienen objetivos didácticos. La satisfacción de necesidades afectivas y la interacción con otras personas es fundamental y el entorno familiar responde a éstas.

\footnotetext{
${ }^{4}$ Esta idea está asociada a la dimensión social del tiempo.

${ }^{5}$ Resulta indispensable distinguir entre rol y función. El primero es una característica del individuo y la segunda, el objetivo de una arreglo institucional u organizacional.
} 
En una primera etapa, las necesidades que genera el cuidado de la salud, están determinadas por enfermedades que tienen su origen en factores endógenos, ligados a condiciones genéticas y al cuidado que recibe la madre durante el embarazo y a factores ambientales que producen enfermedades infecciosas y parasitarias. En la prevención y tratamiento de estos padecimientos el rol central lo juegan los padres y más específicamente la madre de familia, quien necesita el apoyo de personal especializado ubicado en organizaciones dedicadas al cuidado de la salud del ámbito estatal o privado. Para la sociedad y la familia, es de la mayor importancia la atención médica concentrada en abatir las enfermedades que inciden sobre la mortalidad infantil. Sobrevivir durante el primer año de vida significa para muchos niños de nuestros países, garantizar la sobrevivencia cuando menos hasta la edad adulta, si la violencia no acaba con su vida en la adolescencia.

A las necesidades de la infancia responde en primera instancia la familia; sin embargo, conforme la sociedad se desarrolla, la familia no cuenta con recursos para enfrentar además del cuidado de la salud de los niños, la amplia gama de necesidades de formación educacional, ni puede afrontar muchos de los riesgos que se derivan de las condiciones de vulnerabilidad del infante, especialmente en lo que a la atención de enfermedades se refiere. Riesgos que, en el ámbito de la salud, en proporciones significativas, colocan a los niños en peligro de muerte si el Estado a través de los sistemas de protección a la salud y el mercado, por medio de los servicios médicos privados, no les prestaran atención.

La mención de las necesidades en materia de cuidados a la salud permite introducir conceptos fundamentales como son el riesgo, la vulnerabilidad y los peligros asociados a la existencia de los individuos.

Una ecuación fundamental para definir la creación de los arreglos institucionales y el papel de las organizaciones en la atención de las necesidades de la población, es precisamente aquella que hace evidente que el riesgo es una función de los peligros que pueden afectarle y las condiciones de vulnerabilidad del ser humano; función que de manera formal puede expresarse matemáticamente como sigue:

Riesgo $=$ Peligro $\mathrm{x}$ Vulnerabilidad, de tal manera que, para incidir sobre el Riesgo, se debe actuar sobre los peligros y la vulnerabilidad.

El riesgo, es la probabilidad de que se presente un evento que nos produce un daño, el peligro es la fuente del daño y la vulnerabilidad la condición que incide sobre la probabilidad de que ocurra el evento dañino.

Como debe ser evidente, cada uno de los componentes de la ecuación mencionada, objeto de nuestro interés, se modifican a lo largo de la vida 
del ser humano y es indispensable identificar que la vulnerabilidad puede ser una condición acumulativa, de aquí que el riesgo adquiera también este carácter. Así, las problemáticas del envejecimiento demográfico tienen que ver precisamente con la vulnerabilidad creciente de la población, asociada no sólo a sus determinantes biológicos, también, y de manera significativa, a sus determinantes sociales, los cuales tienen una incidencia diferencial entre los grupos que conforman la sociedad.

La observación de un indicador como la esperanza de vida al nacimiento y al primer año de vida a lo largo de varias décadas, en México, con datos que se presentan en la Tabla 1, muestra el resultado de acciones del Estado en materia de salud pública, modificaciones del entorno para hacerlo más saludable y la aplicación de la ciencia y la tecnología a la salud que permitieron que la mortalidad infantil se abatiera y con ello se incrementara la sobrevivencia. Así, se incidió sobre el riesgo de muerte, actuando sobre peligros y vulnerabilidad.

En el pasado, los cuidados de la familia fueron, para proporciones significativas de la población, claramente insuficientes para garantizar la supervivencia durante el primer año de vida y resultaron privilegiados quienes ya avanzado el siglo XX, tuvieron acceso a los servicios de salud del sistema de seguridad social y específicamente los servicios del Instituto Mexicano del Seguro Social.

En la Tabla 1 se observan diferencias de más de cinco años entre la esperanza de vida al nacimiento y la esperanza de vida a la edad uno, que se reducen sistemáticamente hasta prácticamente desaparecer con el siglo XXI. Esta reducción de las diferencias es multifactorial, pero se puede mencionar que ha sido especialmente importante la intervención estatal para incidir en la mortalidad infantil, al mejorar las condiciones sanitarias de las localidades en donde reside la población, ampliar el acceso a los servicios médicos administrados por el Estado y más recientemente, como una acción concreta que implica la participación de las madres en la atención de los infantes, la promoción del uso de la terapia de rehidratación oral (TRO) para tratar a los niños que sufren enfermedades diarreicas y las campañas para erradicar las enfermedades prevenibles por vacunación.

En el caso de estas acciones concretas que he mencionado, es un eufemismo decir, que la familia, que incluye a todos sus miembros, jugo un papel fundamental en la implementación de medidas de cuidado de la salud. Es el rol de las madres lo que permite abatir las enfermedades y la muerte de sus hijos, a partir de una condición inicial: el abandono de actitudes fatalistas para las cuales la enfermedad y la muerte son mandato divino. 
Tabla 1: México. Esperanza de vida al nacimiento y al primer año de edad, por sexo y por quinquenios de 1950-1955 a 2010-2015

\begin{tabular}{|c|c|c|c|c|c|c|c|}
\hline $\begin{array}{l}\text { Esperanza de } \\
\text { vida por sexo }\end{array}$ & $\begin{array}{l}1950 \\
1955\end{array}$ & $\begin{array}{l}1960 \\
1965\end{array}$ & $\begin{array}{l}1970 \\
1975\end{array}$ & $\begin{array}{l}1980 \\
1985\end{array}$ & $\begin{array}{l}1990 \\
1995\end{array}$ & $\begin{array}{l}2000 \\
2005\end{array}$ & $\begin{array}{l}2010 \\
2015\end{array}$ \\
\hline \multicolumn{8}{|l|}{ Hombres } \\
\hline $\mathrm{e}_{0}$ & 48.92 & 56.42 & 60.09 & 64.44 & 68.53 & 70.43 & 72.13 \\
\hline $\begin{array}{l}\mathrm{e}_{0} \\
\text { Mujeres }\end{array}$ & 55.43 & 61.63 & 64.09 & 67.02 & 70.09 & 71.60 & 72.96 \\
\hline $\mathrm{e}_{0}$ & 52.54 & 60.58 & 65.15 & 71.16 & 74.51 & 76.44 & 78.17 \\
\hline $\mathrm{e}_{0}$ & 57.86 & 64.53 & 68.31 & 73.19 & 75.94 & 77.50 & 78.90 \\
\hline
\end{tabular}

Es decir, junto con garantizar el acceso a los medios para evitar o combatir enfermedades, hubo que transformar la conducta de las madres para que aceptaran que, en gran medida, en sus manos está la sobrevivencia de sus hijos. Este ejemplo, hace evidente que al interior de la familia existen roles de importancia diferencial en la satisfacción de las necesidades de sus miembros y es la mujer jefa de familia o cónyuge del jefe de familia, quien ocupa generalmente el papel más importante.

Una situación que se hace visible con el desarrollo de la sociedad es que, durante la infancia, cada vez más el mercado y el Estado intervienen en el cuidado de los infantes a través de centros de atención para esta población, como las guarderías administradas privada o públicamente. Esta, es una respuesta a dos procesos: por una parte, la satisfacción de necesidades de educación que deben ser satisfechas por personal especializado ya que, además, asistir a la escuela tiene efectos positivos en el desarrollo de niñas y niños al fomentar en los centros educativos la interacción con otros individuos y, por otra parte, la participación creciente de las mujeres en la actividad económica fuera del espacio doméstico, reduce la posibilidad que las madres dispongan de tiempo suficiente para la atención y cuidado cotidiano de sus hijos en el hogar.

Después de los primeros años de vida una organización: la escuela, adquiere cada vez mayor importancia en el desarrollo de los individuos y en el caso de México, la escuela pública cumple mayoritariamente este papel. La provisión de servicios de educación básica se convierte en una obligación estatal.

La entrada a la escuela define para la niña o el niño un nuevo rol: el de estudiante. El individuo debe cumplir con las obligaciones que implica éste rol que nos prepara para la vida en ésta y en etapas posteriores. 
Las organizaciones que responden directamente a las necesidades de la niñez son la familia, el Estado y el mercado en ese orden de importancia. Siendo la familia el elemento a través del cual el Estado y el mercado inciden sobre los infantes. Si bien el rol central del niño debe ser el de estudiante, en lo económico los infantes cumplen con el rol de consumidores, con algunas excepciones en las cuales también son productores, ya que combinan la escuela con el trabajo, generalmente en la unidad económica familiar y sólo en una mínima proporción no asisten a la escuela. Según los datos más recientes, entre los 6 y los 12 años de edad casi 98 por ciento de las niñas y niños en México asisten a la escuela ${ }^{6} \mathrm{~A}$ la familia se le asigna la supervisión de la asistencia a la escuela de niños y jóvenes y los arreglos institucionales, a través de leyes, normas o reglamentos lo definen. En este caso, en México, el Artículo 31 de la Constitución Política establece como primera obligación de los mexicanos: "Hacer que sus hijos o pupilos concurran a las escuelas públicas o privadas, para obtener la educación preescolar, primaria, secundaria, media superior..."

En la infancia, la vulnerabilidad es una condición que se encuentra asociada al proceso de maduración física y mental y, por tanto, la educación y los cuidados personales que le brindan otras personas a las niñas y los niños, son fundamentales para incidir sobre su desarrollo. Sin embargo, es común que las enseñanzas para sobrevivir y que transmiten hábitos de higiene, alimentación y cuidados de la propia integridad física, descuiden las necesidades afectivas por ignorancia o incapacidad real para responder a ellas. Se puede originar en esta etapa un Síndrome de Carencia Afectiva que afectará de muy distintas formas el desarrollo del individuo.

Lo importante en esta etapa, es que se asume que vulnerabilidad y dependencia, son condiciones pasajeras que se transformaran durante el transcurso del tiempo, para hacer del individuo un ser cada vez más independiente. Mantener condiciones de dependencia a partir de la infancia, generalmente se origina en problemas de salud que no pueden ser superados o que, por carencias en la familia, ya sean económicas o de conocimiento de los problemas, no son atendidos adecuadamente.

Los arreglos institucionales para atender a la infancia tienen un objetivo central muy claro, para utilizar una expresión de uso común en la actualidad, "la creación de capital humano", es decir la preparación para enfrentar el futuro de manera independiente; sin embargo, es probable que la transmisión de valores, indispensable para mantener la cohesión social e impulsar el desarrollo sean relegadas a un segundo plano.

${ }^{6}$ Datos de la Encuesta Intercensal 2015, INEGI, 2016 b. 
La interacción social se amplía en la escuela y en la comunidad. La necesidad de ocupar el tiempo libre en actividades que requieren otros espacios, que no son ni la residencia familiar ni la escuela, es cada vez mayor y con ello riesgos y peligros de sufrir daños a la salud y a la integridad física, se incrementan, asociados a prácticas en donde la violencia y el consumo de drogas ilegales pueden además de afectar la integridad física del adolescente, costarle la vida.

La adolescencia es una etapa en la cual además del rol de estudiante, las condiciones económicas, es decir, la inserción en la estructura social, puede obligar a las personas jóvenes que asisten a la escuela, a cumplir también el rol de trabajador en una actividad económica que le genere ingresos. El adolescente puede ser consumidor y productor al mismo tiempo. Por lo que para el mercado el adolescente adquiere mayor visibilidad. Este doble rol de estudiante y trabajador caracteriza al adolescente de ciertos grupos socioeconómicos, cuyas condiciones los obligan a generar ingresos para satisfacer las necesidades propias y las necesidades de la familia. Aunque el Estado mantenga el carácter gratuito de la educación, el joven no puede permanecer en la escuela porque, además de no serle atractiva, ni parecerle útil para lograr en el futuro un empleo bien remunerado, puede ser un lujo mantenerse como estudiante ante la necesidad de trabajar. Esto explica que en esta etapa se observen las mayores tasas de deserción en la educación. Los datos más recientes, correspondientes al año 2015, muestran que, aunque los jóvenes declaran que la razón principal de abandono escolar en la educación media es la falta de recursos económicos (38 por ciento) y le sigue en orden de importancia que abandona la escuela porque lo "dieron de baja por reprobar materias", un análisis estadístico más detallado en el que se controlaron diversos factores, hace evidente que las condiciones que generan el mayor riesgo de abandono escolar son el embarazo en la adolescencia, la reprobación de materias, el considerar que los estudios no son de utilidad, la asignación de clases en un turno no deseado y la falta de recursos económicos, en ese orden de importancia /SEP-INSP, 2015). Es decir, la falta de recursos económicos aducida como razón para abandonar los estudios esconde otras razones que tienen que ver con conductas riesgosas o falta de interés en los estudios.

Ante el reconocimiento de la dificultad que tienen proporciones significativas de familias de acceder a la educación y mantener a los adolescentes como estudiantes, el Estado interviene a través de políticas públicas para retenerlo en la escuela. En México, las acciones más importantes en esta materia además de garantizar la gratuidad de la educación, están consti- 
tuidas por los programas de becas para estudiantes de educación media y superior, que son relativamente nuevos, ya que en el pasado se consideraba que el Estado sólo estaba obligado a garantizar servicios de educación gratuita de nivel básico y la familia debería ser la organización que asumiera el costo de la educación de mayor nivel. Así, aunque la educación media y superior puede ser gratuita si la ofrece el Estado sin cobrar por estos servicios en universidades y escuelas públicas, mantener a un estudiante representa un costo significativo para muchas familias.

Para el mercado, ofrecer servicios de educación se convierte en una actividad atractiva, ante el crecimiento de la demanda de estos servicios y la dificultad de las universidades públicas por satisfacerla, tanto por falta de capacidades físicas como por la percepción entre amplios sectores de la población de que la calidad de la educación pública es mala. El crecimiento de los servicios privados de educación superior muestra una tendencia claramente al alza, como lo muestran las cifras de estudios al respecto (Muños Izquierdo y Silva Laya, 2013: 81-101). Para las empresas, ofrecer servicios de educación es un gran negocio; para la sociedad, ésta una acción que contribuye a la segmentación social, al dejar sin oportunidad de estudiar a muchos jóvenes que no pueden pagar por estos servicios.

Como se menciona en párrafos anteriores, el embarazo aparece estadísticamente como el factor causal más importante de abandono escolar y es que, en la adolescencia, la sociedad y la biología definen a los jóvenes nuevos roles ligados a la actividad sexual y reproductiva. ${ }^{7}$

En la adolescencia, las necesidades afectivas no sólo las cumple la familia, éstas son satisfechas por otros individuos, con los cuales pueden llegar a establecerse relaciones sexuales y/o afectivas, que reafirman su identidad y a partir de las cuales se puede formar una nueva familia, en cuyo caso, los arreglos institucionales formales o informales reconocen estas relaciones y definen derechos y obligaciones para los sujetos involucrados.

Los arreglos institucionales se vuelcan sobre el individuo joven para hacerlo un sujeto productivo. El Estado y el mercado, tienen cada vez mayor relevancia en la satisfacción de las necesidades de la población joven y pueden interactuar directamente con el individuo, sin que la instancia de intermediación sea la familia.

La familia ve disminuida su esfera de influencia en las conductas de los adolescentes y sólo es aceptada mayoritariamente por ellos mismos, como una organización para satisfacer sus necesidades básicas.

${ }^{7}$ La fiesta de 15 años, en la tradición mexicana, ha constituido un rito de pasaje mediante el cual la familia anuncia a la sociedad que uno de sus miembros, "la quinceañera" está lista para representar el rol de adulto, tener hijos y formar una pareja conyugal. 
Las y los adolescentes perciben a la familia y el Estado como arreglos institucionales que, al proponerse satisfacer sus necesidades, en realidad limitan sus libertades y es el mercado en donde consideran que pueden ejercer su libertad, a través del consumo de mercancías y servicios que satisfacen necesidades, que, en gran proporción, el propio mercado crea. Es en esta etapa en donde se hace cada vez más evidente que la satisfacción de una necesidad lleva al surgimiento de otra nueva y es el mercado el mecanismo que lo propicia.

Los adolescentes, se consideran ellos mismos invulnerables, simplemente por haber sobrevivido a las enfermedades que los atacaron en la infancia y evitar otras que no hicieron mella en ellos, por recibir los beneficios de la vacunación, en gran medida a través de los programas de salud pública implementadas por el Estado, hasta llegar a una edad en la cual pueden ejercer su independencia. Sin embargo, aunque los problemas de salud ocasionados por enfermedades que tiene gran incidencia en la infancia disminuyen, nuevas situaciones de riesgo aparecen asociadas a las prácticas sexuales y al uso del tiempo libre, en actividades que dañan su salud e incluso les pueden provocar la muerte.

Consumo de drogas y alcohol, prácticas sexuales sin protección y deportes de alto riesgo, forman parte de la actividad de muchos jóvenes, que el mercado fomenta, el Estado pretende controlar y la familia parece ignorar o no puede controlar por falta de autoridad y recursos materiales.

La vulnerabilidad en la adolescencia se encuentra asociada a las condiciones propias de un individuo aún dependiente y en proceso de maduración sicológica y a su inserción en la estructura social como parte del grupo familiar al que pertenece, que le permiten acceder y disfrutar de los satisfactores de sus necesidades en el seno de la familia. En esta etapa, se hace evidente que las condiciones de vida en la infancia influyen en los adolescentes a través de lo que se puede denominar "genética social", es decir, la transmisión de valores y recursos materiales entre generaciones, que marcan al individuo en cada una de las etapas de su ciclo vital.

Los problemas ligados a la imposibilidad de acceder a instituciones educativas, deserción escolar e la imposibilidad de encontrar empleo, generan escenarios que no pueden ser modificados significativamente desde el ámbito familiar. El mercado, por cierto, contribuye al crecimiento de esta problemática, por lo que el rol del Estado para atender las necesidades de esta población adquiere mayor importancia.

Proveer de educación, vivienda y empleo, para los jóvenes, son acciones básicas en cualquier sociedad que busque su desarrollo y es el Estado el ente que puede promoverlas. 
Si las acciones del Estado para atender a la infancia deben garantizar su cuidado y educación y la familia es la organización intermediaria para hacerlo, para tender a la adolescencia las necesidades se multiplican junto con el número y naturaleza de las organizaciones en las cuales deben ser satisfechas.

El adolescente que no puede o no quiere asumir el papel de estudiante, requiere de empleo. Estado y mercado juegan un papel cada vez más importante, pero sus limitaciones para satisfacer las necesidades de los jóvenes tienen que ser asumidas por la familia, en cuyo seno permanecen a edades cada vez más elevadas.

Debe mencionarse, que originada en situaciones económicas por las cuales los jóvenes no pueden independizarse, la adolescencia perece ampliarse y éstos permanecen más tiempo en la casa de los padres. Esta situación se ve reflejada en la información más reciente proveniente de la Encuesta Nacional de los Hogares 2015, que muestra en México, que uno de cada cuatro jóvenes de 30 a 34 años de edad residen aún en la casa de sus padres. ${ }^{8}$

En la etapa adulta y en el ámbito económico en el cual el mercado define el papel de los individuos, los roles de productor y consumidor compiten entre sí, mientras que, en el ámbito familiar, se asume que las personas al iniciar este periodo de su ciclo vital, deben asumir la función maternal o parental, para garantizar la reproducción de la sociedad.

Las condiciones de vulnerabilidad del adulto afectan de manera central el cumplimiento del rol de proveedor para sí mismo o para quienes dependen de su persona, lo que se asume como rol central en el caso de los hombres y a las mujeres se les identifica con el rol de madre, aunque cada vez más, ellas cumplen el papel de proveedor en combinación con su cónyuge e incluso el de proveedor único de la familia. Por lo tanto, para los adultos, el acceso al empleo y su estabilidad laboral, son fundamentales para reducir su vulnerabilidad, no sólo en determinadas coyunturas, sino como elementos que le permitan acumular los activos indispensables para enfrentar el futuro, en situaciones cada vez de mayor incertidumbre. Por lo tanto, el Estado interviene en el ámbito laboral a través de la seguridad social para ofrecer servicios de cuidado de la salud y garantizar al adulto la obtención de ingresos cuando carece de empleo a través del seguro de desempleo; sin embargo, ante las bajas coberturas de la seguridad social y la limitada generación de empleos formales en el mercado de trabajo, el empleo informal es el refugio de un número creciente de adultos, que

\footnotetext{
${ }^{8}$ Cálculos propios a partir de la base de datos de la ENH-2015.
} 
si bien obtienen ingresos no tienen acceso a los servicios de salud o lo tienen en los programas públicos con grandes limitaciones. Por su parte, la familia se convierte en la red de apoyo de los adultos sin empleo, o con empleo en condiciones económicas precarias, ya sean estos los propios hijos, o los cónyuges de sus hijos y los hijos de los hijos, ya que, según la conseja popular, "en donde comen dos, comen tres o cuatro". Muestra de esta situación es el porcentaje de hogares ampliados que en 2015 (según datos de la ENH) representa 24 por ciento del total.

Cada una de las etapas del ciclo vital ya mencionadas se hace cada vez más extensa, simplemente por la ampliación de la sobrevivencia, situación que debe destacarse porque es el origen de la gran paradoja del desarrollo en el siglo XXI, que representa el éxito de la sociedad, al lograr que vivamos más tiempo y su fracaso, si no se pueden proveer condiciones aceptables de sobrevivencia para los viejos.

Por lo que hace a la evolución de la esperanza de vida, su incremento es evidente a lo largo del periodo representado en la Tabla 2 y es una muestra objetiva del abatimiento de los riesgos de muerte prematura y la ampliación, especialmente significativa, de la sobrevivencia en la vejez.

Tabla 2: Esperanza de vida al nacimiento, a los 60 y a los 65 años de edad para hombres y mujeres en diversos quinquenios del periodo 1950, 2050

\begin{tabular}{lccccc}
\hline \multicolumn{5}{c}{ Quinquenios } \\
\hline & 1950 & 1970 & 2000 & 2020 & 2045 \\
& 1955 & 1975 & 2055 & 2025 & 2050 \\
\hline Hombres & & & & & \\
Al nacimiento & 48.9 & 60.1 & 70.4 & 73.6 & 76.5 \\
A los 60 años & 15.1 & 17.5 & 19.9 & 21.1 & 22.1 \\
A los 65 años & 12.2 & 14.5 & 16.5 & 17.4 & 18.3 \\
Mujeres & & & & & \\
Al nacimiento & 52.5 & 65.2 & 76.4 & 79.7 & 82.7 \\
A los 60 años & 16.1 & 19.1 & 22.7 & 24.4 & 26.1 \\
A los 65 años & 13.0 & 15.6 & 18.8 & 20.4 & 21.0 \\
\hline
\end{tabular}

Fuente: CELADE, 2003. América Latina y el Caribe. El envejecimiento de la población.

Debe destacarse para los propósitos de este texto, la diferencia en la esperanza de vida entre mujeres y hombres, que elimina la idea simplona de que las mujeres constituyen "el sexo débil", y obliga a pensar en las condiciones sociales que deben cumplirse para que la población que sobrevive más años, en este caso, la población femenina, lo haga con sus necesidades satisfechas. 
No parece haber duda de que, las acciones de las organizaciones creadas para atender las necesidades de la población desde el nacimiento hasta la adolescencia, se encuentran plenamente justificadas funcionalmente y aceptadas en todos los sectores de la sociedad, independientemente de la visión ideológica de los observadores, porque las organizaciones están actuando en la creación de los activos de la sociedad. Incluso, entre algunos grupos socioeconómicos, cada nueva generación de hijos desde la infancia constituye un activo para la familia y específicamente, las generaciones de adultos suponen que los hijos constituirán un seguro para enfrentar la vejez, ante las limitaciones de la seguridad social o su ausencia definitiva entre amplios sectores de la población.

Sin embargo, la atención de los viejos en el ámbito familiar, por parte de otros de sus miembros y en especial de sus hijos, ni se asume ni se acepta, cuando se hace evidente que la carencia de recursos propios los convierte en un pasivo que demanda atención creciente que no se puede proveer por falta de recursos económicos y capacidades.

La construcción del ser humano para participar en sociedad constituye una tarea a la cual la familia, el Estado y el mercado contribuyen para mantener su viabilidad, lo que no necesariamente hace que los objetivos de cada ámbito institucional coincidan.

A través de las etapas del ciclo vital descritas en párrafos anteriores, es claro que los arreglos institucionales y las organizaciones que se derivan de éstos, en forma muy limitada responden a la creación de condiciones estructurales para enfrentar la vejez y sólo de manera parcial les dan elementos a las personas para sobrevivir en condiciones aceptables. No obstante, aceptando estas limitaciones institucionales, puede afirmarse que llegar a la vejez o formar parte de una sociedad cada vez más envejecida, es la manifestación del triunfo de la sociedad sobre la naturaleza por lo que estamos obligados a proponer acciones para ser viejos con el mayor número de necesidades satisfechas y la mejor calidad de vida posible.

\section{EL ENVEJECIMIENTO CENTRO DE ATENCIÓN INSTITUCIONAL EN EL SIGLO XXI}

Para hacer propuestas que pongan especial atención al contexto institucional que requiere una sociedad en proceso acelerado del envejecimiento, debe reiterarse la mención a las condiciones de vida de la población de edad avanzada, que reflejan no solamente sus determinantes biológicos, también sus determinantes sociales, porque es fundamentalmente sobre 
éstos, que los arreglos institucionales y las organizaciones a las que dan origen, pueden actuar para modificar su incidencia.

Un primera hipótesis central para generar los arreglos institucionales que permitan atender las necesidades de los viejos, consiste en suponer que las condiciones de vida en edades avanzadas, son tanto el resultado de situaciones coyunturales y comportamientos previos asumidos a lo largo de la vida de las personas, como de factores específicos que actúan sobre el individuo con resultados diferenciales, de acuerdo con sus propias características biológicas y su inserción en la estructura social.

Esta hipótesis que puede parecer en extremo simplista y obvia, no está presente en los modelos teóricos que sirven de base al diseño de políticas para atender a los viejos, ni constituyen una premisa para hacer consciente a los miembros de una familia ni al individuo, que la vejez es inminente porque cada vez tenemos mayores probabilidades de alcanzarla y que, por tanto, debemos contar con recursos para enfrentarla.

Una segunda hipótesis, es que, para lograr sus objetivos, los arreglos institucionales creados para atender las necesidades de los viejos, deben reconocer que la perspectiva para atenderlos con los recursos materiales que esto demanda, debe tomar en cuenta la manera en que la sociedad genera y distribuye su riqueza, es decir, es necesaria una perspectiva basada en la economía política.

Así, por ejemplo, si prestamos especial atención a las condiciones de vulnerabilidad de la población de edad avanzada para actuar sobre ella, debemos suponer que ésta tiene un carácter acumulativo ligado por supuesto a la edad, pero también a condiciones estructurales y, por tanto, es indispensable identificar los determinantes directos a través de los cuales, la estructura social genera estados de vulnerabilidad.

Para responder a la necesidad de crear arreglos institucionales y organizaciones que respondan a las necesidades de los viejos y dado que el envejecimiento es un fenómeno global, a nivel internacional se han hecho esfuerzos para contar con un diagnóstico sobre las condiciones de vida de la población en edades avanzadas, que presente objetivamente su situación. Con tal propósito, en años recientes La organización HelpAge International, a través de sus asociados ha construido lo que en español se denomina Índice Global de Envejecimiento. ${ }^{9}$

Este índice

ha sido diseñado para alentar el debate entre la sociedad civil y los tomadores de decisiones sobre el envejecimiento de la población y sus desafíos, y para

${ }^{9}$ Organización que ha coordinado esta tarea es HelpAge International 
promover una mejora en la elaboración de políticas públicas. (Este índice) Busca resaltar las fortalezas y debilidades de las respuestas estratégicas frente a los desafíos del envejecimiento de la población (HelpAge International, 2013).

Como puede observarse por los objetivos expresados, la generación de este indicador complejo, elaborado a partir de una serie de indicadores simples, reconoce que los problemas del envejecimiento, deben enfrentarse hoy día, pensando en el futuro, es decir, considerando el mediano y largo plazo. Este índice, resulta ser una herramienta útil para nuestro propósito ya que esta perspectiva implica el reconocimiento del papel que juegan los arreglos institucionales para responder a las demandas del envejecimiento demográfico.

El índice se calculó para 96 países, para los cuales se contaba con información suficiente para generarlo y se ordenaron de tal manera que, el número 1, ocupado por Suiza, se consideró la nación en la cual las personas de la "tercera edad", tienen las mejores condiciones de vida y Afganistán en la posición 96, es el país en donde esta población tiene las peores condiciones de vida. ${ }^{10}$

Sin tener la intención de describir la metodología para la construcción de este Índice, que está basado en los procedimientos usados en la construcción del índice de Desarrollo Humano del Programa de Naciones Unidas para el Desarrollo, ${ }^{11}$ vale la pena destacar los aspectos conceptuales que le dan origen y específicamente sus cuatro componentes que reflejan las condiciones de vida de los viejos: i) seguridad de ingresos, ii) estado de salud, iii) competencias y iv) entornos favorables.

A través de estos cuatro componentes, se cuantifican las condiciones de bienestar de esta población y lo que es más importante, es que en el modelo teórico que le da sustento, se considera que: i) las personas mayores tienen derecho a contar con una pensión que les asegure un "ingreso decente"; ii) la gente tiene aspiraciones para tener buena salud en la vejez; iii) que las personas mayores tienen capacidades y atributos para mantener su bienestar; y finalmente, iv) la base del bienestar es la libertad y capacidad para lograrlo. ${ }^{12}$

Las premisas anteriores, colocan en el centro de la atención aquellos factores sobre los que se debe actuar con una visión estratégica, es decir,

\footnotetext{
10 Índice Global de Envejecimiento en HelpAge International (2013).

${ }^{11}$ El lector interesado en conocer la metodología puede revisar: HelpAge International 2013. Global AgeWatch Index 2013. Purpose, methodology and results.

${ }^{12}$ Ver: Conceptual considerations in measuring quality of life and wellbeing of older people, en HelpAge International (2013).
} 
con una visión transversal de largo plazo y no sólo con acciones coyunturales.

Los resultados más recientes en el Índice de Envejecimiento 2015, se presentan a continuación en la Tabla 3 para los países de América Latina y el Caribe, para los cuales se calculó, con los valores de cada uno de los componentes.

Tabla 3: Índice global de envejecimiento, países de América Latina y el Caribe.

Rango total y por componentes, 2015

\begin{tabular}{lrrrrr}
\hline País & $\begin{array}{r}\text { Índice } \\
\text { General }\end{array}$ & $\begin{array}{r}\text { Seguridad de } \\
\text { ingresos }\end{array}$ & $\begin{array}{r}\text { Estado } \\
\text { de salud }\end{array}$ & $\begin{array}{r}\text { Competencias } \\
\text { favorables }\end{array}$ \\
\hline Panamá & 20 & 40 & 31 & 16 & 48 \\
Chile & 21 & 43 & 14 & 22 & 49 \\
Uruguay & 27 & 8 & 37 & 38 & 57 \\
Costa Rica & 28 & 52 & 15 & 60 & 29 \\
Argentina & 31 & 20 & 40 & 34 & 66 \\
México & 33 & 36 & 35 & 62 & 46 \\
Colombia & 36 & 69 & 18 & 47 & 42 \\
Ecuador & 44 & 56 & 28 & 72 & 58 \\
Perú & 48 & 68 & 32 & 30 & 79 \\
El Salvador & 54 & 77 & 34 & 59 & 53 \\
Bolivia & 55 & 55 & 59 & 37 & 78 \\
Brasil & 56 & 13 & 43 & 58 & 87 \\
Nicaragua & 57 & 76 & 45 & 68 & 33 \\
Guatemala & 59 & 74 & 44 & 81 & 34 \\
República & 62 & 80 & 39 & 57 & 43 \\
Dominicana & 69 & 79 & 50 & 54 & 77 \\
Paraguay & 69 & 66 & 29 & 51 & 93 \\
Venezuela & 76 & 85 & 46 & 73 & 65 \\
Honduras & 82 & & & &
\end{tabular}

Fuente: HelpAge International, 2013.

No es mi intención hacer un análisis de los resultados de la construcción de este Índice ni de la información a partir de la cual es generado y que, considero que en la práctica tiene limitaciones derivadas de la naturaleza transversal de la información en que se basa y de los indicadores usados en cada uno de los componentes. Lo importante es el modelo conceptual al que responde que, desde mi punto de vista, permite identificar los factores sobre los que debemos actuar para enfrentar el problema del envejecimiento y garantizar condiciones de vida adecuadas para los viejos. ${ }^{13}$

${ }^{13}$ Por ejemplo, una primera limitación de este Índice es que, aunque se reconoce que se debe considerar que la situación actual que vive un individuo o grupo de individuos responde en gran medida a condiciones generadas previamente, el Î́ndice Global de Envejecimiento, proporciona 
Aceptando estas limitaciones, los indicadores de cada componente, son un esfuerzo por tener una visión totalizadora, "holística", como se suele llamar en la actualidad, de las condiciones de vida de los viejos, que permita diseñar acciones para mejorarlas.

En el caso de un primer indicador como "Seguridad de ingresos", que está formado por cuatro componentes que son: i) cobertura de ingresos proveniente de pensiones; ii) tasa de pobreza en la vejez, iii) bienestar relativo de las personas mayores, y iv) PIB per cápita, cada uno de los tres primeros componentes debería representar condiciones derivadas de los beneficios de la seguridad social y del proceso de acumulación de riqueza, representado por el ahorro que es posible hacer a lo largo de la vida.

Un primer aspecto a destacar, es considerar la naturaleza de las pensiones y estimar la relación entre pensiones contributivas y no contributivas. Por una parte, son las pensiones contributivas las que están ligadas a los aportes que hacen los trabajadores al ahorro generacional que les permitirá contar con recursos para enfrentar la vejez, una vez que cumplen con ciertos requisitos como tiempo de ahorro (cotización) y edad. Por otra parte, las pensiones no contributivas, constituyen en realidad transferencias monetarias de carácter asistencial para quienes no lograron ahorrar lo suficiente para la vejez y, por tanto, a través de acciones de política social se realiza una transferencia de recursos a la población que está por debajo de niveles mínimos de bienestar. En cualquiera de sus modalidades forman parte de la Seguridad Social y el Estado garantiza su existencia. Sin embargo, las aportaciones de los trabajadores, los patrones y el Estado a la Seguridad Social puede no ser suficiente, para garantizar una pensión adecuada a las necesidades del asegurado, en función de los montos ahorrados, la estabilidad o inestabilidad en el empleo y la evolución económica, que puede ser desfavorable a este ahorro social.

La información reciente para México, por ejemplo, muestra que el porcentaje de la población de adultos mayores que recibe una pensión proveniente de la seguridad social es muy bajo, apenas una de cada cuatro personas de 65 años o más. ${ }^{14}$ Para enfrentar esta baja cobertura, se han implementado Programas asistenciales a través de los cuales el Gobierno

\footnotetext{
"una perspectiva de la generación actual de personas adultas mayores..., en lugar de considerar cómo, las experiencias anteriores de la vida influyen en los resultados observados en la vejez. Las excepciones son los indicadores sobre el nivel educativo e ingresos por pensiones, resultados de experiencias anteriores de vida" (HelpAge International, 2013: 11). Si bien es comprensible la dificultad de reflejar en un índice la influencia de condiciones previas, no es posible descartar estas influencias, sobre todo, por ejemplo, en el caso de la salud.

${ }_{14}$ Datos de la Encuesta de Ingreso y Gasto de los Hogares 2014, INEGI y la Encuesta de la Dinámica Demográfica 2015, INEGI. La estimación de la población de 65 o más años en 2015 es de casi nueve millones de personas, por lo que el número de pensionados es de 2.4 millones.
} 
Federal o los Gobiernos Estatales hacen transferencias monetarias a los adultos mayores. Las denominaciones y características de los programas varían por entidad; sin embargo, el aspecto más relevante es su carácter universal en entidades como la Ciudad de México. Para el país en su conjunto, 42.4 por ciento de esta población recibe beneficios de estos programas por lo que, cuando se hacen estimaciones de la cobertura de ingresos provenientes de pensiones se llegan a cifras extremadamente altas, ya que a las pensiones contributivas se suman las pensiones no contributivas. ${ }^{15}$

Al separar las fuentes de ingreso de los viejos según el arreglo institucional en que se originan, se observa en México que, además de la pensión como fuente de ingresos, entre los adultos mayores, conforme aumenta la edad, porcentajes crecientes reciben transferencias de recursos de otros hogares, lo que representa en este país, diez por ciento de personas de 65 o más años; sin embargo, este porcentaje llega a 14 por ciento entre las personas de 85 o más años. Además, como es posible suponer, las transferencias familiares tienen mayor significación entre las personas que no reciben una pensión. Es decir, las familias aportan en forma significativa para la sobrevivencia de los viejos, reduciendo la disponibilidad de ingresos per cápita en la familia que hace estas aportaciones. (datos para México provenientes de ENADID-2104).

Por otra parte, el mercado, específicamente el mercado laboral, representa entre los viejos un ámbito de participación significativa en el que obtienen remuneraciones por el trabajo que realizan ya que, hasta los 75 años de edad, uno de cada cuatro adultos mayores desempeña un trabajo por el cual recibe ingresos. Además, entre esta población es poco significativo el porcentaje que vive de sus rentas (dos por ciento, con datos de la ENADID-2014) es decir, resulta una característica casi universal que los viejos carecen de activos que generen ingresos para sobrevivir en esta etapa de su vida.

Aunque los porcentajes de la población que carece de cobertura pensional son altos, esto no significa que, para sobrevivir, todos los adultos mayores tengan que contar con una fuente de ingresos propia, ya que pueden depender directamente de un familiar que se haga cargo de cubrir sus necesidades básicas. Es decir, la familia es responsable de su sobrevivencia. Sin embargo, en años recientes la disminución en el tamaño de las familias ha hecho que cada vez sean más los adultos mayores que no cuentan con el apoyo familiar. Desaparecen las familias grandes en cuyo seno los viejos

${ }^{15}$ La estimación de HelpAge International, para el porcentaje total de personas de 65 o más años de edad que en México recibe una pensión es de 88 por ciento, pero este porcentaje incluye pensiones contributivas y no contributivas. 
sobrevivían y, por tanto, incluso, son cada vez más los viejos que viven solos. Esto no quiere decir, que en el pasado una gran proporción del total de familias se hacían cargo de los viejos, llegar a viejo era una situación extraordinaria. En 1930, menos de tres por ciento de la población tenía 65 o más años de edad y apenas 0.6 por ciento de la población tenía 80 años o más.

En México, en el año 2014, en casi un millón de hogares vive sola una persona de 65 o más años de edad, lo que representa 3.2 por ciento de los hogares (el total de los hogares unipersonales de 60 años o más, es de 1.3 millones, y representa cuatro por ciento).

Ante el panorama descrito, se hace evidente la importancia del Estado en la sobrevivencia de los viejos a través de las transferencias gubernamentales. En el caso de México, el 25 por ciento de las personas de 65 o más años reciben ingresos exclusivamente de programas gubernamentales. ${ }^{16}$

Además, la insuficiencia de la pensión que reciben quienes están cubiertos por la seguridad social, hace que los pensionados recurran a los programas gubernamentales de transferencias de recursos. (diez por ciento en el caso de México).

Como es obvio, la manera que tienen los viejos para contar con ingresos suficientes para sobrevivir, no puede ligarse al trabajo, ya que ni están en condiciones de desarrollarlo ni existe un mercado que demande su participación.

Las soluciones que se han propuesto en esta materia sólo pueden funcionar parcialmente para un limitado número de estas personas y estas iniciativas se concretan a ofrecerles un espacio para realizar una actividad que, de acuerdo con sus condiciones puede generarles recursos económicos. En este sentido, no es exagerado plantear que, como producto del envejecimiento, la tarea de "empacador" en un supermercado, ha pasado a ser una actividad de los ancianos que antes, estaba reservada originalmente a los jóvenes e incluso a los niños, como forma de "apoyarlos en sus estudios". Es decir, la pauperización visible entre los infantes es también una condición de los viejos. A los "niños de la calle", preocupación histórica de las organizaciones de asistencia social, sumaremos los "viejos de la calle".

No es posible estimar el número de ancianos que en México se desempeñan como empacadores en las tiendas de autoservicio, porque en las empresas en que trabajan, al considerar que éste es un trabajo voluntario, no llevan registro del personal que realiza esta tarea y asumen que son ellos mismos los que se organizan para llevarla a cabo y no mantienen ningún

\footnotetext{
${ }^{16}$ Cálculos propios basados en la ENADID 2014.
} 
tipo de relación laboral, lo único que reconocen las empresas es que dan su anuencia para permitirles estar en la línea de cajas empacando la mercancía que los clientes han comprado, para lo cual en México, el Instituto Nacional de las Personas Adultas Mayores (INAPAM) celebra convenios con las empresas a las que acuden los empacadores.

Con toda seriedad, el Instituto Nacional de las Personas Adultas Mayores (INAPAM) por medio de su Programa de Inclusión Productiva a través del Sistema de Empacado Voluntario de Mercancías, se encarga de promover esta actividad entre los adultos con 60 o más años de edad, "ya que todavía tienen mucho que aportar a la sociedad, participan con entusiasmo, con amabilidad, aportan su experiencia y conocimientos por lo que las empresas empleadoras reconocen su valía". ${ }^{17}$

Aunque puede ser poco significativo numéricamente el número de empacadores ancianos, ${ }^{18}$ los ingresos que reciben equivalen a un monto que va de dos salarios mínimos hasta cuatro veces el salario mínimo por día de trabajo (estimación del autor a través de entrevistas a estas personas en tiendas de autoservicio), por lo que se convierte en una actividad atractiva para quien la desempeña. Es probable, además, que todos los adultos mayores que trabajan de empacadores reciban ingresos de los programas gubernamentales de transferencias monetarias dedicados a esta población ya que como los ingresos que reciben son producto de las propinas que les otorgan los clientes, no se considera un salario y por tanto no infringen ninguna normatividad.

Deben ser bienvenidas todas las iniciativas laborales que pretendan incidir positivamente en las condiciones de vida de los viejos, pero suponer que los adultos mayores pueden y deben trabajar, es desconocer las condiciones físicas que muestran y el deterioro que se sufre con la edad. Estas iniciativas para emplear a los viejos, además, tienen poco efecto sobre el conjunto de esta población, porque entre quienes más lo necesitan, son muy pocos los que pueden ser empleados.

En la situación actual, la seguridad social vinculada a la participación de los individuos en el mercado laboral formal, no es la solución para garantizar a los viejos su sobrevivencia y satisfacer sus necesidades básicas, porque cada vez una menor proporción tiene trabajo con prestaciones sociales. Con los niveles de desempleo y empleo informal en nuestros países, sólo transformaciones estructurales que tengan como fin la gene-

${ }^{17}$ Declaraciones del delegado del INAPAM en el estado de Aguascalientes al periódico Plano Informativo el día 11 de septiembre de 2015.

${ }^{18}$ Algunas estimaciones sitúan en 30 mil el número de ancianos empacadores a nivel nacional, según registros del INAPAM. 
ración de empleo productivo y suficientemente remunerado, pueden ser la solución de largo plazo a la problemática ligada al envejecimiento demográfico, pero los millones de adultos mayores que necesitan satisfacer sus necesidades y contar con los recursos para hacerlo, demandan acciones inmediatas.

En esta materia, es indispensable proponer la Pensión Universal que garantice ingresos para todos los viejos, más allá de programas asistenciales de carácter coyuntural y sujetos a decisiones políticas. De la misma manera que se asignan por ley en los presupuestos públicos recursos para ofrecer servicios en diversas áreas que responden a las demandas de la población, deben considerarse recursos para la Pensión Universal al llegar a la vejez.

Se está avanzando en esta materia con acciones específicas, que, si bien reconocen el derecho a tener una vida digna, no establecen obligaciones que deban cumplir los individuos, que tengan también un carácter universal, aunque diferenciadas por la capacidad de las personas para cumplirlas.

En la línea de análisis propuesta, ligada al Índice Global de Envejecimiento, un segundo componente al que se debe hacer referencia es el "Estado de salud", sobre el que es necesario actuar y que en este es el representado por tres indicadores:

1. Esperanza de vida a los 60 años.

2. Esperanza de vida saludable a los 60 años.

3. Bienestar psicológico.

La ampliación de la sobrevivencia observable claramente en la esperanza de vida alcanzada a los 60 años de edad, permite que la convivencia intergeneracional sea una situación generalizada. Hoy, un individuo promedio que llega a los 60 años, puede esperar vivir 20 años más. Así, a los individuos pertenecientes a una cohorte, sobrevivan padres, abuelos y bisabuelos, sin que esto sea un caso extraordinario; pero al mismo tiempo, esta convivencia implica un mayor tiempo y recursos dedicados al cuidado de los viejos, porque con la edad la dependencia se incrementa, fundamentalmente por el deterioro del estado de salud, con demandas de los viejos a las que no siempre puede responder la familia por la naturaleza de las enfermedades de los individuos de edad avanzada que requieren de atención especializada; con una agravante adicional, como ya se mencionó, las familias numerosas que podían aportar al cuidado de sus ascendientes o entre cuyos miembros una de las hijas se hacía cargo de los padres, han desaparecido. 
Se observa en la Tabla 4 que una persona que alcance los 60 años de edad, es posible que viva en la actualidad en promedio alrededor de 20 años y en el caso de las mujeres que viva aún más. Sin embargo, también es probable, que enfrente situaciones de discapacidad cada vez más graves conforme envejezca. Una proporción importante de las discapacidades se origina en el efecto de las enfermedades crónico-degenerativas y las lesiones que se producen los viejos en sus propios hogares o en su entorno cercano.

Es importante destacar que la naturaleza de las enfermedades de los viejos, hacen imposible que la familia sea la institución que se haga cargo de su cuidado, porque a la enfermedad original, se suman con gran frecuencia condiciones de discapacidad que limitan la movilidad de las personas.

Tabla 4: México. Esperanza de vida a los 60 años de edad para hombres y mujeres en diversos quinquenios del periodo 1950, 2050

\begin{tabular}{lccccc}
\hline \multicolumn{5}{c}{ Quinquenios } \\
& 1950 & 1970 & 2000 & 2020 & 2045 \\
& 1955 & 1975 & 2005 & 2025 & 2050 \\
\hline Hombres & & & & \\
A los 60 años & 15.1 & 17.5 & 19.9 & 21.1 & 22.1 \\
$\begin{array}{l}\text { Mujeres } \\
\text { A los 60 años }\end{array}$ & 16.1 & 19.1 & 22.7 & 24.4 & 26.1 \\
\hline Fuente: Celade, 2003. & & &
\end{tabular}

Estas condiciones de vulnerabilidad se derivan de lo que llamaré acumulación del déficit social que se manifiesta en riesgos diferenciales de vivir con limitaciones que, en el extremo, llevan a la pérdida de la vida.

Por cierto, el análisis de las condiciones de vulnerabilidad asociadas a la discapacidad en la vejez, hace indispensable tomar en cuenta la pertenencia a cierto grupo social, porque éste es claramente un factor diferenciador.

En el ámbito internacional se ha demostrado que las poblaciones con mayor mortalidad tienen también una mayor prevalencia de discapacidad (ver, por ejemplo, los informes sobre la Salud en el Mundo elaborados por la OMS).

Lo que determina las condiciones de vulnerabilidad de la población de edad avanzada, está relacionado con los niveles de discapacidad y las limitaciones en el ejercicio de su autonomía para satisfacer las necesidades básicas. Una aproximación a las condiciones de esta población la ofrecen los datos de censos, encuestas y estudios especializados, que muestran el porcentaje de la población de 60 años o más, que declara alguna condición 
de discapacidad y que hacen evidente que, con el avance de la edad, los niveles de autonomía se ven disminuidos significativamente hasta una situación en la cual alrededor del treinta por ciento de la población de $75 \mathrm{o}$ más años de edad, muestra signos de deterioro físico, que son especialmente importantes porque limitan su capacidad de desplazarse. Pero incluso, a partir de los 60 años de edad, casi 15 por ciento de los individuos son incapaces de valerse por sí mismo para desarrollar actividades elementales para su sobrevivencia (ENADID, 2014).

El mejoramiento de la tecnología y los cambios en los estilos de vida pueden incidir sobre la edad de aparición de las enfermedades crónicas y posponer la edad de la muerte, sin embargo, como ya se mencionó, las discapacidades parecen tener una incidencia significativa sobre las personas a partir de los 65 años de edad.

Con respecto al estado de salud de la población de edades avanzadas, además de la información sobre distintos tipos de incapacidades, con la que tradicionalmente se cuenta, la Encuesta Nacional de los Hogares 2015 (ENH-2015), captó información sobre "salud emocional" y específicamente sobre depresión. ${ }^{19}$ A partir de estos datos, se observa que entre la población de 65 o más años de edad, una de cada cuatro personas tiene problemas de memoria y a partir de 85 años este porcentaje supera el 50 por ciento. Respecto a la depresión, 40 por ciento de los individuos de 65 o más años, declaran tener episodios frecuentes de depresión y el 12 por ciento sufre de depresión severa. ${ }^{20}$

Con las condiciones descritas, en el seno de la organización familiar no hay ni capacidad ni deseo para cuidar a los viejos que lo necesitan y cuando este cuidado puede otorgarse, son generalmente las hijas quienes lo proveen limitando sus propias condiciones de vida. ${ }^{21}$ Las Encuestas sobre Uso del Tiempo, muestran lo importante que resulta entre la población femenina el número de horas que dedican al cuidado de otros miembros de la familia y en especial de los viejos. ${ }^{22}$

\footnotetext{
${ }^{19}$ La ENH-2015, incluyó un conjunto de 23 preguntas para captar la percepción sobre aspectos referentes al estado de salud de los integrantes del hogar en cuanto a dificultades en visión, audición y movilidad y la salud emocional a partir de los siete años de edad, con información relacionada con la existencia, frecuencia e intensidad de sentimientos de preocupación o nerviosismo, depresión o dolor.

${ }^{20}$ Cálculos propios a partir de la base de datos de la ENH-2015.

${ }^{21}$ Los datos de la Encuesta Nacional de Familia, realizada por el autor muestran que sólo 15 por ciento de la población entrevistada mayor de 14 años considera que es obligación de los hijos cuidar a sus padres.

${ }^{22}$ Con la Encuesta Nacional sobre Uso del Tiempo, se estima que las mujeres dedican 26 horas a la semana a prestar "cuidados especiales a integrantes del hogar por enfermedad crónica, temporal o discapacidad" y de este total se dedican 18 horas a las personas de 60 o más años de edad (INEGI, 2014).
} 
Otro componente que define las condiciones de vida de la población de edad avanzada, que se incluye en el Î́ndice de Envejecimiento Global es el que se denomina "Entornos favorables" y que hace referencia básicamente a la existencia de vínculos sociales que establecen los adultos mayores con su entorno.

El aislamiento se convierte en una condición generalizada en el caso de los viejos, por sus propias condiciones físicas y la falta de apoyo familiar y la negación de relaciones afectivas que comprometen a las generaciones más jóvenes.

La carga que representaran los viejos para las generaciones más jóvenes, la ilustran las cifras de un indicador denominado "necesidad de apoyo a los padres", desarrollado por el Centro Latinoamericano de Demografía (Tabla 5). ${ }^{23}$

Tabla 5: Relación numérica de necesidad de apoyo a los padres (por cien). México 1950-2050

\begin{tabular}{lrrrrr}
\hline & \multicolumn{5}{c}{ Año } \\
& 1950 & 1975 & 2000 & 2025 & 2050 \\
\hline Relación & 4.9 & 11.3 & 9.8 & 11.1 & 25.1 \\
\hline
\end{tabular}

Fuente: Celade, 2003.

Los viejos que tienen hijos requieren de su apoyo, pero, a diferencia de la idea generalizada de que los hijos se harán cargo de sus progenitores durante su vejez, los datos más recientes muestran que la realidad está lejos de este escenario optimista. En la Encuesta Nacional de Familia, cuando se pregunta: "En una familia formada por padres e hijos, ¿Cuál es la obligación de los hijos hacia los padres?", 80 por ciento declara que respetarlos, pero sólo 15 por ciento, considera que es su obligación apoyarlos en la vejez (Welti, 2015).

La existencia de redes sociales incide sobre el ambiente en el que transcurre la vida cotidiana de los individuos y permite acceder a recursos de diversa naturaleza: ayuda en la realización de actividades o tareas, recursos materiales como alimentos, medicinas o ropa, o bien recibir un préstamo o una transferencia monetaria.

El cuestionario usado en el Modulo de Condiciones Socioeconómicas (MCS) anexo a la Encuesta de Ingresos y Gastos de los Hogares(ENIGH) 2015, incluyó una sección sobre la percepción de acceso a redes socia-

\footnotetext{
23 "Es la medida comúnmente usada para expresar la demanda familiar de apoyo a sus ancianos. La relación de apoyo a los padres es un indicador aproximado de los cambios requeridos en los sistemas familiares de apoyo a los ancianos. Es el cociente entre las personas de 80 o más años de edad y las personas entre 50 y 64 años de edad" (Celade, 2003).
} 
les que respondieran a necesidades específicas de las personas. Entre la población de 65 o más años de edad, 47 por ciento considera que sería difícil o "imposible" conseguir ayuda si necesitara cuidados cuando estuviera enfermo y el 30 por ciento considera que sería difícil o "imposible" si necesitara que lo acompañaran a ver al doctor. Esta percepción muestra la importancia de contar con apoyos institucionales ante la aparición de estas necesidades y lo relevante que son programas como el denominado "El médico en tu casa" implementado por el gobierno de la Ciudad de México para atender a la población vulnerable entre la cual se identifica a los adultos mayores. ${ }^{24}$

Ante los niveles de dependencia de los adultos de edades avanzadas, que están asociados a sus condiciones económicas y de salud, habrá que evaluar el efecto que a nivel familiar tendrá en el mediano y largo plazo, la reducción en el número de hijos sobre las condiciones de sobrevivencia de los viejos.

Puede suponerse, por una parte, que la caída de la fecundidad hubiera tenido efectos positivos sobre la capacidad de ahorro de los padres, que tendrían que dedicar menos recursos a la atención de los hijos al reducirse su número; sin embargo, en un contexto de creciente informalidad e inestabilidad en el sector laboral, del crecimiento del empleo precario en el sector formal y con grandes dificultades para que los jóvenes encuentren empleo, la dependencia que tienen éstos de sus padres, se alarga y se convierte en una carga económica para ellos, que ha sido diferida de la infancia a la juventud de los hijos y que por tanto, aunque el número de hijos se haya reducido, impacta la capacidad de ahorro en el seno de la familia.

Por otra parte, a nivel macroeconómico, el monto del gasto social que en décadas pasadas estuvo dedicado a la atención de la población infantil, se ha traslado a la población de mayor edad, cuyos requerimientos en materia de atención a la salud representan un costo muy superior.

Resulta paradójico que el desequilibrio financiero de las instituciones encargadas de proveer servicios de salud se explique por el excesivo aumento de los costos que ocasiona el cambio demográfico y epidemiológico; en especial, la atención a las enfermedades crónico-degenerativas y el cada vez más acelerado incremento de la población de edad avanzada, cuando estos cambios, son el resultado de los éxitos de las políticas en materia de salud.

En términos de políticas públicas, es decir, de acciones del Estado a través de sus agencias y de acciones de la familia o del mercado, es indis-

\footnotetext{
${ }^{24}$ El Programa incluye también atención a mujeres embarazadas con embarazos de alto riesgo.
} 
pensable tomar en cuenta cada uno de los aspectos de la realidad que los "componentes" e indicadores del índice Global de Envejecimiento reflejan y que han sido descritos previamente, para actuar sobre ellos.

Aunque cada uno de los ámbitos de acción institucional responde a la necesidad de remediar situaciones del momento o coyunturales, es necesario insistir en que debe prevalecer en su tratamiento, una visión longitudinal de largo plazo, porque los problemas del envejecimiento son manifestaciones del carácter acumulativo de las condiciones individuales y de situaciones estructurales que inciden en la población a lo largo de su ciclo de vida y que aparecen en la vejez.

\section{REFLEXIONES Y RECOMENDACIONES SOBRE EL ESCENARIO ACTUAL QUE GENERA EL ENVEJECIMIENTO DEMOGRÁFICO}

Es cada vez más claro que, a los ejes diferenciadores sustantivos de la sociedad que a través de la historia han sido: clase, raza y género, en décadas recientes debe sumarse uno más, la edad. Y, a posiciones discriminatorias clasistas, racistas o sexistas debemos identificar posiciones etaristas, que generan una discriminación basada en la edad de los individuos.

Aunque ésta ha sido llamada la discriminación no reconocida, algunos demógrafos llamamos tempranamente la atención sobre su inminente aparición en la sociedad, conforme la transición demográfica avanzaba y la esperanza de vida se incrementaba.

En materia de empleo, mencionábamos ya los especialistas en esta materia, desde hace algún tiempo que en el mundo del trabajo esta situación se haría más evidente. El primer indicio surgió cuando la oferta de trabajo llamaba a ocupar las plazas disponibles siempre y cuando "el aspirante fuera menor de 40 años".

La pregunta que surge es: ¿con qué argumentos es posible que se limite el acceso al trabajo a las personas que lleguen a cumplir 40 años? o, mejor dicho, ¿cuáles son las razones sociales, culturales o económicas por las que se discrimina a las personas que llegan a esta edad? La respuesta a estas preguntas permite entender las raíces estructurales de esta discriminación, que pretende asegurar la productividad de la mano de obra, sin tomar en cuenta las condiciones cambiantes de la demografía de la sociedad.

No debe sorprender que la OIT apenas iniciada la segunda mitad del siglo XX, reconociera la discriminación en el empleo como un problema que debe ser atacado por los Estados miembros de la Organización, aunque también debe decirse que, en 1958 en el Convenio y la Recomendación 
sobre la Discriminación, ${ }^{25}$ la edad no aparece como característica que dé origen a algún tipo de discriminación ya que se identifican únicamente: raza, color, sexo, religión, opinión política, ascendencia nacional u origen social; a menos que se considere que la edad entre en: "cualquier otra distinción, exclusión o preferencia que tenga por efecto anular o alterar la igualdad de oportunidades o de trato en el empleo u ocupación".

No es mi interés centrar mi atención en el análisis del documento de la OIT, pero me parece muy sugerente que no es sino más de dos décadas después que la propia Organización "Recordando que el Convenio y la Recomendación sobre la discriminación (empleo y ocupación), 1958, no incluyen la edad entre las causas de discriminación en ellos enumeradas, pero prevén la posibilidad de ampliar la lista de dichas causas", ${ }^{26}$ adopta una muy significativa recomendación al considerar que la edad puede generar discriminación, y toma en cuenta el proceso de envejecimiento. Sin embargo, sus recomendaciones carecen de viabilidad, en una sociedad en la que los estados nacionales han estado empeñados en impulsar en el ámbito de lo laboral, una reforma estructural que tiene como objetivo lo que se denomina la flexibilización, que entre otras cosas se caracteriza por la desaparición de la contratación colectiva y la generalización de la contratación temporal, lo que atenta con la posibilidad de los trabajadores de acumular recursos suficientes para afrontar la vejez.

Regreso a la época en la que la OIT está preocupada por la discriminación (1958) y no debe sorprender que no se ponga especial énfasis en la edad porque nos encontramos en aquel momento con una población que en promedio tenía una esperanza de vida al nacimiento que no superaba los 50 años. Vale la pena recordar que en 1960, la población de un gran número de países tenía una esperanza de vida por debajo de $60 \mathrm{años}^{27}$ y las preocupaciones en materia de empleo eran otras y eso explica que sólo décadas después se haya visto la necesidad de elaborar una recomendación como la que se menciona, porque a diferencia de un Convenio Internacional cuyo cumplimiento debe ser obligatorio por parte de los Gobiernos firmantes, una Recomendación es únicamente eso y se convierte entonces en una expresión de buenos deseos.

La Recomendación multicitada, sin embargo, reconoce de manera clara la problemática laboral ligada al envejecimiento. La OIT recomienda para

\footnotetext{
${ }^{25}$ Convenio sobre la discriminación (empleo y ocupación), 1958 (núm. 111). Organización Internacional del Trabajo. Ginebra.

${ }^{26}$ Recomendación sobre los trabajadores de edad,1980 (162). 66 Reunión CIT. Organización Internacional del Trabajo. Ginebra.

${ }^{27}$ En Latinoamerica y el Caribe, sólo Cuba, Argentina y Uruguay tenían en 1958 una esperanza de vida que superaba los 60 años.
} 
las personas de edad reducir la duración normal del trabajo, diaria y semanal, en aquellos casos en los que el individuo esté dedicado a ocupaciones penosas, peligrosas o insalubres y fomentar la reducción progresiva de la duración del trabajo de todos los trabajadores de edad que así lo solicitasen e incrementar las vacaciones anuales pagadas en función de la antigüedad o de la edad. ¿Será posible generar estas condiciones ante el problema del acelerado envejecimiento y garantizar que el trabajador cuente con los recursos para enfrentar la vejez ${ }^{28}$

La Recomendación de la OIT concluye mencionando que "Deberían adoptarse medidas para asegurar que se informe plenamente a los trabajadores de edad avanzada de los derechos y posibilidades a su alcance y se los incite a utilizarlos". Y yo agregaría, antes de que estos derechos desaparezcan.

Debo subrayar que las consideraciones de la OIT con respecto al trabajo de las personas de edad, son una llamada de atención para atender de manera responsable los problemas que en esta materia trae consigo el envejecimiento y que si no son atendidos provocarán la desintegración acelerada del tejido social.

Una situación significativa es que la población de la tercera edad está compuesta en su mayoría por mujeres especialmente en las áreas urbanas, donde las diferencias de mortalidad tienden a ser más importantes. Así, además de las problemáticas mencionadas, la evolución de la mortalidad que acompaña al proceso de envejecimiento puede repercutir tanto sobre los patrones de corresidencia y tipos de hogares como sobre las relaciones intrafamiliares, ámbitos que no han sido atendidos institucionalmente ni por la familia, ni el mercado ni el Estado, cuando menos en el caso de México.

En materia de salud, todas las recomendaciones que sirven de fundamento a las políticas públicas y las acciones de la familia, ponen énfasis en la necesidad de reducir los costos de atención de las enfermedades crónico-degenerativas, pero esto contradice las acciones del mercado que

\footnotetext{
${ }^{28}$ Sería interesante identificar en que sector económico se aceptarían este tipo de medidas, si una queja frecuente de los empresarios es que no podemos competir con otros países por el costo de la mano de obra y tienen razón, especialmente si fijamos nuestra atención en países tan remotos geográficamente y tan cercanos económicamente como China, en donde encontramos condiciones de trabajo en extremo deprimidas y en donde el régimen autoritario impide cualquier demanda de los trabajadores por mejorar estas condiciones, que hacen atractiva la ubicación de las grandes corporaciones en este país, si a esto sumamos un tipo de cambio totalmente favorable a las exportaciones, es efectivamente difícil pensar que estas recomendaciones puedan implementarse, sin transformar un modelo económico para que el objetivo central sea la ampliación del mercado interno.
} 
fomentan prácticas que inciden sobre los factores de riesgo de sufrir estas enfermedades.

Nuestros países tienen todavía una estructura por edad joven, pero un escenario en el cual uno de cada cuatro habitantes tenga más de 65 años, se presentará en las próximas décadas y sin duda que las demandas de sus habitantes y la oferta institucional para enfrentar éstas tendrán que modificarse significativamente.

Precisamente, a algunos aspectos de esta problemática quedan definidos a partir de la concepción que se tiene de ésta y las condiciones de vida de los viejos.

El envejecimiento se percibe como uno de varios "males" demográficos. Es decir, bajo ciertos enfoques es común considerar a los problemas sociales como "enfermedades" y, por tanto, plantear su solución a través de medidas terapéuticas que atienden más a sus manifestaciones externas que a solucionar los problemas en sus raíces.

En esta visión epidemiológica, la edad se considera un factor de riesgo y se sobrestima su papel, negando visibilidad a las condiciones estructurales que condenan a grandes proporciones de viejos a la pobreza.

Como la dimensión temporal en la que se ubican los fenómenos sociales es el eje central a partir del cual éstos deben interpretarse, en el caso de lo demográfico al ser representado este eje por la edad, los problemas demográficos a nivel individual en las primeras etapas del ciclo vital se considera que desaparecen con el paso del tiempo. Los problemas de la infancia o la adolescencia terminan conforme avanza el calendario, pero no sucede lo mismo con los problemas de la vejez y ante la imposibilidad de esperar que la situación se modifique positivamente conforme la edad se acumula, al proceso de envejecimiento en la edad adulta se le trata de dar una connotación distinta a la que se vive cotidianamente, como si ser viejo deseara evitarse y no asumirse como condición elemental de sobrevivencia y éxito de la sociedad en la batalla por enfrentar los factores que producen la muerte.

Al reconocer las consecuencias que la estratificación etaria de la sociedad tiene para la vida de los individuos se adquiere conciencia sólo tardíamente de lo que en una sociedad como la nuestra significa ser viejo. Para evitar la toma de conciencia y exigir transformaciones de la sociedad, se propone una visión idílica de esta etapa de la vida, inventando adjetivos como "tercera edad", "población añosa", "juventud acumulada" hasta llegar a la denominación de "adultos en plenitud", como si la denominación de esta población transformara la situación de los viejos. 
Debemos recuperar el uso del adjetivo viejo como el que "se aplica a las personas... de mucha edad" y dejemos de considerar el adjetivo viejo como despectivo y al envejecimiento como una enfermedad.

Es especialmente importante en la coyuntura actual una reflexión sobre el envejecimiento y el papel del Estado, el mercado o la familia, porque ni el mercado ni la familia son arreglos institucionales que aseguren la sobrevivencia de los viejos en condiciones aceptables.

La sociedad vive un proceso de envejecimiento acelerado con una estructura institucional que ya no corresponde a las nuevas condiciones demográficas del país; sin embargo, el problema no es un asunto que pueda resolverse con medidas que obliguen a la población a ahorrar para el futuro, para enfrentar, por ejemplo, sus problemas de salud en la vejez, cuando una gran proporción de los viejos no tiene capacidad de ahorro. Éste es un asunto ligado a la distribución de la riqueza que genera la sociedad y como tal debe enfrentarse con instrumentos de política social, política económica y política fiscal, tema éste último que parece intocable en México.

\section{REFERENCIAS BIBLIOGRÁFICAS}

CELADE, 2003, América Latina y el Caribe: el envejecimiento de la población. Centro Latinoamericano de Demografía. Santiago de Chile.

HelpAge International, 2013, Global AgeWatch Index 2013. Purpose, methodology and results.

INEGI, 2014, Encuesta Nacional sobre Uso del Tiempo, Tabulados Básicos, Instituto Nacional de Estadística y Geografía, Aguacalientes.

INEGI, 2015, Encuesta de Ingreso y Gasto de los Hogares 2014, Instituto Nacional de Estadística y Geografía, Aguascalientes.

INEGI, 2016a, Encuesta de la Dinámica Demográfica 2015, Instituto Nacional de Estadística y Geografía, Aguascalientes.

INEGI, 2016b, Encuesta Intercensal 2015, Instituto Nacional de Estadística y Geografía, Aguascalientes.

Keynes, John M., 1923, A tract on monetary reform. MacMillan and Co. Limited. London.

Maslow, A. H., 1943, “A Theory of Human Motivation”, in Psychological Review, 50, 370-396. 
Muños Izquierdo, Carlos y Silva Laya, Marisol, 2013, "La educación superior particular y la distribución de oportunidades educativas en México", en Revista de la educación superior, vol. 42 (2), núm. 166, abril-junio, pp. 81-101.

SEP-INSP, 2015, Análisis del movimiento contra el abandono escolar en la educación media superior, Secretaría de Educación e Instituto Nacional de Salud Pública.

Welti, Carlos, 2015, Qué Familia! Encuesta Nacional de Familia. Los mexicanos vistos por sí mismos. Universidad Nacional Autónoma de México. México.

\section{Resumen CURRICUlAR DEL AUTOR}

\section{Carlos Welti Chanes}

Es economista, sociólogo y demógrafo por la Universidad de Chicago. Es investigador titular del Instituto de Investigaciones Sociales de la Universidad Nacional Autónoma de México (UNAM). Es miembro del Sistema Nacional de Investigadores desde su fundación. Ha sido presidente de la Sociedad Mexicana de Demografía, coordinador general del Programa Latinoamericano de Actividades en Población y vicerrector de Investigación y Estudios de Posgrado de la Universidad Autónoma de Puebla. Es profesor de Análisis Cuantitativo del posgrado en la Facultad de Ciencias Políticas y Sociales de la UNAM. Es miembro del Consejo de Administración de la Asociación Mexicana de Planificación Familiar (MEXFAM) y preside su comité técnico. Ha publicado un gran número de trabajos sobre la fecundidad.

Dirección electrónica: welti@servidor.unam.mx

Artículo recibido el 7 de febrero de 2017 y aprobado el 14 de agosto de 2017. 